\title{
1 High-voltage dilute ether electrolytes enabled by regulating interfacial
}

\section{2 structure}

3 Huwei Wang ${ }^{1}$, Jinkai Zhang ${ }^{2}$, Haodong Zhang ${ }^{1}$, Wei $\mathrm{Li}^{1}$, Ming Chen ${ }^{2}$, Qing Guo ${ }^{3,4}$, Kah Chun Lau ${ }^{3}$,

$4 \quad$ Liang Zeng ${ }^{2}$, Guang Feng ${ }^{2, *}$, Dengyun Zhai ${ }^{1, *}$, Feiyu Kang ${ }^{1, *}$

$5 \quad{ }^{1}$ Shenzhen Geim Graphene Center, Institute of Materials Research, Tsinghua Shenzhen International

6 Graduate School, Tsinghua University, Shenzhen 518055, China.

$7 \quad{ }^{2}$ State Key Laboratory of Coal Combustion, School of Energy and Power Engineering, Huazhong

8 University of Science and Technology (HUST), Wuhan, China.

$9{ }^{3}$ Department of Physics and Astronomy, California State University Northridge, CA, USA.

$10 \quad{ }^{4}$ Department of Physics, Michigan Technological University, MI, USA.

11 *Correspondence: gfeng@hust.edu.cn (G.F.); zhaidy0404@sz.tsinghua.edu.cn (D.Z.);

12 fykang@tsinghua.edu.cn (F.K.) 


\section{SUMMARY}

14 Poor oxidation stability of ether solvents at the cathode restricts the use of dilute ether 15 electrolytes with conventional concentrations around $1 \mathrm{M}$ in high-voltage lithium metal batteries.

16 Here we develop an anion-adsorption approach to altering the ether solvent environment within 17 the electrical double layer (EDL) at the cathode, by adding a small amount of nitrate, so that the 18 oxidation tolerance of nitrate-containing dilute ether electrolytes is enhanced up to $4.4 \mathrm{~V}$ (versus $\left.19 \mathrm{Li} / \mathbf{L i}^{+}\right)$, leading to complete compatibility with high-voltage cathodes and exhibiting superior 20 cycling stability. Constant-potential molecular dynamics simulations reveal that ether molecules 21 are mostly excluded from the cathode because of nitrate occupation in the inner layer of the EDL, 22 thus suppressing ether oxidative decomposition. This work highlights that regulating the 23 interfacial structure by adding surface adsorbates, rather than passivating cathode-electrolyte 24 interphase or changing ion solvation, can help to enhance the oxidation stability of ether solvents. 25 It also provides design criteria for adsorption-type additives to achieve high-voltage dilute ether 26 electrolytes.

\section{KEYWORDS}

28 ether electrolytes; high-voltage electrolytes; electrical double layer; interfacial structure; lithium metal 29 batteries 
31 Electrolytes are of great importance to various electrochemical energy storage systems, particularly 32 high-energy-density lithium (Li) metal batteries (LMBs). ${ }^{1,2}$ Among different electrolytes for LMBs 33 (including solid-state or polymer electrolytes, ${ }^{3,4}$ ionic liquids ${ }^{5}$, and so on), conventional organic 34 electrolytes are still the most widely used electrolytes for LMBs ${ }^{6-8}$ A promising electrolyte that is 35 stable against reactive Li metal anode and high-voltage cathodes at the same time is highly desirable. ${ }^{6,9}$ However, metallic $\mathrm{Li}$ is difficult to be compatible with commonly used organic carbonate solvents due to their low redox potential ( $-3.04 \mathrm{~V}$ versus the standard hydrogen electrode) $){ }^{9-11}$ since solid-electrolyte interphase forms on the $\mathrm{Li}$ anode as a result of uncontrollable electrochemical reduction of carbonate electrolytes, which is chemically unstable and mechanically fragile. ${ }^{6,8}$ To have better reductive stability with Li metal, ether solvents are undoubtedly more attractive for LMBs compared to carbonates. ${ }^{12-14}$ However, conventional dilute ether electrolytes, ${ }^{15,16}$ which have salt concentrations of around $1 \mathrm{M}(\mathrm{M}$, moles per liter of solution), have long been excluded from being used with high-voltage cathodes, such as $\mathrm{LiCoO}_{2}$ and $\mathrm{LiNi}_{x} \mathrm{Mn}_{\mathrm{y}} \mathrm{Co}_{1-\mathrm{x}-\mathrm{y}} \mathrm{O}_{2}(\mathrm{NMC})$, due to their low oxidation stability (less than $4 \mathrm{~V}$ vs. $\left.\mathrm{Li} / \mathrm{Li}^{+}\right) .{ }^{8}$ Consequently, dilute ether electrolytes have usually been utilized in LMBs with cathodes below $4 \mathrm{~V}$ (for example, $\mathrm{LiFePO}_{4}$ and sulfur). ${ }^{17,18}$ Therefore, research on the design of dilute ether electrolytes with extraordinary oxidation stability has drawn much attention and become one of the frontiers in the battery community. ${ }^{19}$

The early entry of ether electrolytes for high-voltage LMBs adopted the high-concentration formulations (e.g., triglyme and tetraglyme solvents with equimolar Li salt). ${ }^{20}$ Although the oxidation stability can be improved to $\sim 5 \mathrm{~V}$ on the platinum electrode, only limited cycling stability (200 cycles) was achieved on the $\mathrm{LiCoO}_{2}$ cathode with a cutoff voltage of $4.2 \mathrm{~V}$. Until now, the high-concentration ether electrolytes ${ }^{14,21,22}$ and localized high-concentration ether electrolytes ${ }^{23,24}$ effectively developed for 4.3/4.4 V NMC cathodes have all followed the same design concept, namely, high salt/solvent molar ratio. ${ }^{16}$ Meanwhile, elimination of unbound (free) solvents of electrolyte ${ }^{16,22}$ and formation of stable cathode-electrolyte interphase $(\mathrm{CEI})^{13,14,21,23}$ have become generally accepted views on the improved oxidation stability. In particular, the high-concentration ether electrolytes usually suffer from 
57 the economic effectiveness, high viscosity and slow dynamics. ${ }^{15,16}$ Even for the localized high58 concentration electrolyte formulation evaluated for practical applications, ${ }^{23,24}$ the usage of 59 hydrofluoroether diluents still results in possible environmental hazards. ${ }^{25}$ Hence, compared with these 60 salt-concentrated solutions, dilute ether electrolytes are thus long required to have high-voltage 61 tolerance; however, limited by their intrinsic poor oxidation stability, ${ }^{8}$ such achievements are rarely 62 reported..$^{19}$ Recently, a molecular design strategy was proposed by introducing fluorinated segment 63 into the ether backbone to improve the oxidation stability of ether. ${ }^{26,27}$ These delicately designed ether 64 electrolytes share the common feature of high-voltage tolerance with the hydrofluoroethers. As a consequence, at $1 \mathrm{M}$ salt concentration, these amended ethers have been successfully used with NMC811 cathodes with cutoff voltages up to 4.4/4.6/4.8 V. This molecular design concept is a remarkable breakthrough in ether electrolyte engineering; however, the changes of ether are often not easily handled due to their delicate synthesis technique. Therefore, a simple handling design for achieving high-voltage electrolytes in $1 \mathrm{M}$ salt concentration with ether solvent unchanged is still highly desired.

To achieve this goal, we develop a strategy based on anion adsorption to alter the ether solvent environment within the electrical double layer (EDL) at the cathode. This strategy enables the enhancement of oxidation stability in $1 \mathrm{M}$ imide salt-based 1,2-dimethoxyethane (DME) electrolytes up to $4.3 \mathrm{~V}$, only by adding a small amount of nitrate. The $\mathrm{LMBs}$ coupled with high-voltage $\mathrm{LiCoO}_{2}$ and NMC532 cathodes in these dilute ether electrolytes exhibit superior cycling stability. Although many promising properties of nitrate for Li metal anodes have been reported, ${ }^{28-31}$ very limited progress has been made on nitrate interfacial behavior near the cathode surface. Here, experimental measurements and molecular simulations were combined to elucidate that by regulating the interfacial structure at the cathode, added $\mathrm{NO}_{3}{ }^{-}$could suppress the ether oxidative decomposition, although the additive has little influence on the bulk electrolyte. As a proof of concept, beyond $\mathrm{NO}_{3}{ }^{-}$, we experimentally demonstrated that a series of anions, including $\mathrm{ClO}_{4}{ }^{-}, \mathrm{ClO}_{3}{ }^{-}, \mathrm{H}_{2} \mathrm{PO}_{4}{ }^{-}$and $\mathrm{HPO}_{4}{ }^{2-}$, have similar effects on improving the oxidation stability of ethers. This electrolyte design concept would 83 provide insights into the high-voltage application of low concentration electrolytes in LMBs. 84 Furthermore, this understanding of the electrified interfaces at the molecular level may be applicable 
85 to the community of electrochemistry beyond the battery, such as the electrocatalysis ${ }^{32}$ and

86 electrosynthesis ${ }^{33}$.

87

\section{RESULTS AND DISCUSSION}

\section{Enhanced high-voltage tolerance of ether electrolyte by adding tiny nitrate}

High-voltage tolerance was first evaluated in the cyclic voltammetry (CV) and linear sweep voltammetry (LSV) tests on $\mathrm{Li}|| \mathrm{LiCoO}_{2}$ and $\mathrm{Li} \| \mathrm{Al}$ cells, respectively (Figure $1 \mathrm{~A}$ and Figure $\mathrm{S} 1$ ). When using the $\mathrm{LiCoO}_{2}$ electrode as the working electrode, unlike the low oxidation onset voltage of $\sim 3.9 \mathrm{~V}$ for pristine ether electrolytes of $1 \mathrm{M}$ lithium bis(trifluoromethanesulfonyl)imide (LiTFSI) in DME, the ether electrolyte with $50 \mathrm{mM} \mathrm{NO}^{-}$showed greatly improved oxidation stability by giving a cutoff voltage at $4.4 \mathrm{~V}$ (Figure 1A). To assess the feasibility of adding the nitrate to enable the dilute ether electrolyte under high voltages, LMBs, with a $\mathrm{LiCoO}_{2}$ cathode and $1 \mathrm{M}$ LiTFSI in DME, were cycled at a high charge cutoff voltage of $4.3 \mathrm{~V}$. A low cathode areal loading of $0.3 \mathrm{mAh} \mathrm{cm} \mathrm{cm}^{-2}$ and excess $\mathrm{Li}$ were used to ensure only a small amount of Li metal was cycled, the impact of electrolyte stability on the $\mathrm{Li}$ anode is deliberately minimized. ${ }^{34}$ As shown in Figure $1 \mathrm{~B}$, in only the $7^{\text {th }}$ cycle, the cell with the nitrate-free dilute ether electrolyte failed to reach the cutoff voltage $(<4.2 \mathrm{~V})$, demonstrating that the conventional dilute ether electrolyte has extremely poor high-voltage compatibility. In stark contrast, the $\mathrm{NO}_{3}{ }^{-}$-containing ether electrolyte (i.e., $1 \mathrm{M}$ LiTFSI/DME with $50 \mathrm{mM} \mathrm{LiNO}_{3}$ ) could achieve $93 \%$ capacity retention with a limited polarization increase (Figure S2) after 1000 cycles. In addition to $\mathrm{LiCoO}_{2}$ cathodes, remarkable high-voltage stability (1000 cycles with $89 \%$ capacity retention) was also found in the long-term cycling of NMC532 cathodes (Figure 1D). Furthermore, microscopy images proved that $\mathrm{Al}$ foil cycled in the $\mathrm{NO}_{3}{ }^{-}$-containing dilute ether electrolyte remains intact, whereas pitting corrosion occurred in the pristine ether electrolyte (Figure S3). These results prove the robustness of $\mathrm{NO}_{3}{ }^{-}$-containing dilute ether electrolyte under high voltages. Note that because of the poor oxidation stability of the pristine ether electrolyte at high voltages (Figure 1B and Figure S4), it was not studied further in electrochemical cells.

\section{Little change of CEI stability and ion solvation}


111 Since ether solvent typically decomposes as voltage exceeds $4.0 \mathrm{~V}$ (refs. ${ }^{8,14,19,21}$ ), it is intriguing to 112 unveil how such a small amount of $\mathrm{NO}_{3}{ }^{-}$could boost the oxidation stability of the conventional dilute 113 ether electrolyte at the cathode. Considering that the current common views of electrolyte design, 114 especially with regard to the well-understood salt-concentrated electrolytes, mostly focus on 115 passivating $\mathrm{CEI}^{14,21,23}$ or changing electrolyte ion solvation ${ }^{16}$, similar mechanisms are worthy of being 116 checked here. The first concern is whether a stable protective CEI film is formed in the $\mathrm{NO}_{3}^{-}-$ 117 containing ether electrolyte. We probed the surface structure of the cycled $\mathrm{LiCoO}_{2}$ cathode in $\mathrm{NO}_{3}{ }^{-}-$ 118 containing ether electrolytes using the transmission electron microscope (TEM). Compared to the 119 surface morphology of the bare $\mathrm{LiCoO}_{2}$ (Figure 2A), a clear and intact surface edge can be observed 120 in the representative region of the cycled $\mathrm{LiCoO}_{2}($ Figure $2 \mathrm{~B})-$ a selected region based on extensive 121 TEM characterizations; while in some local regions, a nonuniform amorphous layer (2-10 $\mathrm{nm})$ and 122 gathered nanoscale crystalline grains (assigned to LiF) can be found (Figure S5). The poor 123 homogeneity cannot support the conclusion that an effective surface passivating layer forms in the $124 \mathrm{NO}_{3}{ }^{-}$-containing ether electrolyte.

Meanwhile, the surface chemistry of the cycled $\mathrm{LiCoO}_{2}$ electrodes was probed via the X-ray photoelectron spectroscopy (XPS) measurement. As seen from the fitted O 1s XPS spectra in Figure S6A, compared with the bare $\mathrm{LiCoO}_{2}$ electrode, lattice oxygen at $529.8 \mathrm{eV}$ (shaded area) shows a flatter peak in the cycled $\mathrm{LiCoO}_{2}$ electrodes (50 cycles). The signals $(\mathrm{C}-\mathrm{O}$ and $\mathrm{C}=\mathrm{O})$ from the $\mathrm{CEI}$ components overwhelm the lattice oxygen peak, implying the electrolyte decomposition on the $\mathrm{LiCoO}_{2}$ surface. ${ }^{35,36}$ However, the inorganic signals, especially for the LiF species (56.0 eV in Li 1 s and 684.8 eV in F 1s, Figures S6B and S6C), are not particularly noticeable. This surface can only be identified as an organic-inorganic hybrid surface, which is distinct from the inorganic-dominated surface observed in the salt-concentrated ether electrolytes for high-voltage LMBs. ${ }^{21,23}$ To further confirm the stability of this surface, the $\mathrm{LiCoO}_{2}$ electrodes pre-polarized in the $\mathrm{NO}_{3}{ }^{-}$-containing ether electrolyte were carefully reassembled in the $\mathrm{NO}_{3}{ }^{-}$-free ether electrolyte for sequential cycling (Figure S7). Unfortunately, without the presence of nitrate, the cell with pre-polarized electrode fails to reach the cut-off voltage within the first cycle (Figures S7B and S7D), which is consistent with the behavior observed in Figure 1B. This failure confirms that the surface passivating formed in the $\mathrm{NO}_{3}{ }^{-}$-containing 
ether electrolyte is not stable enough.

140 Moreover, the chemical environment of DME molecules, a frequently mentioned issue in 141 electrolyte design, ${ }^{16}$ is also examined by nuclear magnetic resonance (NMR) spectroscopy. At $1 \mathrm{M}$ 142 LiTFSI electrolyte, the peak of ODME shifts upfield with the increase of $\mathrm{LiNO}_{3}$ concentration (Figure

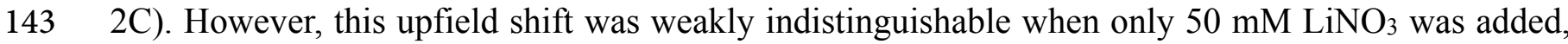
144 suggesting a weakly changed chemical environment of DME in the bulk electrolyte. Even when the 145 concentration of $\mathrm{LiNO}_{3}$ increases to $200 \mathrm{mM}$, this upfield shift remains unnoticeable. Such 146 phenomenon is further confirmed by molecular dynamics (MD) simulations of bulk ether electrolytes, 147 where the number density of DME around $\mathrm{Li}^{+}$is slightly changed when adding $50 \mathrm{mM} \mathrm{LiNO} 3$ and 148 almost unchanged with $\mathrm{LiNO}_{3}$ concentration increasing from $50 \mathrm{mM}$ to $200 \mathrm{mM}$ (Figure 2D). The 149 detailed coordination states are represented in Figure $2 \mathrm{E}$ and $2 \mathrm{~F}$, and Figure $\mathrm{S} 8 \mathrm{C}$, where $\mathrm{NO}_{3}{ }^{-}$partly 150 replaces $\mathrm{TFSI}^{-}$anion but the coordination between $\mathrm{Li}^{+}$and $\mathrm{DME}$ is maintained. Until the $\mathrm{LiNO}_{3}$ 151 concentration reaches $500 \mathrm{mM}$, the replacement of $\mathrm{DME}$ by $\mathrm{NO}_{3}{ }^{-}$in the first solvation shell takes place 152 (Figure 2G). These results demonstrate a slight change of electrolyte ion solvation with additive, which 153 also fails to explain the great improvement of oxidation stability.

Overall, the presence of a small amount of $\mathrm{NO}_{3}{ }^{-}$has little influence on either stable CEI formation or the ion solvation environment in bulk electrolytes, the enhanced oxidation stability of the $\mathrm{LiNO}_{3}-$ containing dilute electrolyte cannot be explained with current knowledge developed in the saltconcentrated electrolytes.

\section{Regulation of interfacial structure by added nitrate}

159 Considering that the electrolyte reactivity originates from the solvent contacting the cathode, a 160 thorough understanding of the aggregation state of different solvent molecules or ions at the electrified 161 interface becomes very crucial. ${ }^{31,37,38} \mathrm{MD}$ simulations with the implementation of the constant 162 potential method ${ }^{39}$ for asymmetric electrode systems with $\mathrm{Li}$ metal anode and $\mathrm{LiCoO}_{2}$ cathode, 163 depicted in Figure S9, were adopted to dissect the EDL structure of pristine and $\mathrm{NO}_{3}^{-}$-containing $1 \mathrm{M}$ 164 LiTFSI in DME at the cathode. For the pristine ether electrolyte, under the positive polarization, a distinct layer of DME molecules within $\sim 0.5 \mathrm{~nm}$ could contact the cathode (Figure 3A), with the vector 
between two $\mathrm{O}$ atoms of a DME molecule mainly parallel to the cathode surface (Figure S10); while with adding a small amount of $\mathrm{NO}_{3}{ }^{-}$, the DME at the cathode is found to be drastically reduced, as illustrated in Figure 3A. Meanwhile, a large accumulation of $\mathrm{NO}_{3}{ }^{-}$anions can be found at the cathode surface, driven by the positive polarization (Figure 3B); interestingly, the number ratio of interfacial $\mathrm{NO}_{3}{ }^{-}$to $\mathrm{TFSI}^{-}$is 0.83 (from the integration of number density in Figure $\mathrm{S} 11$ ), which is far above the ratio in the bulk region $(0.2)$, this remarkable increase of $\mathrm{NO}_{3}^{-}$anions at interface implies the preferential absorption of $\mathrm{NO}_{3}{ }^{-}$for $\mathrm{LiCoO}_{2}$. More importantly, this finding indicates that the interfacial features of $\mathrm{NO}_{3}{ }^{-}$-containing ether electrolyte does not inherit chemical signatures from bulk solution, which is qualitatively different from the high-/super-concentrated electrolytes ${ }^{40-43}$. This preferential absorption of $\mathrm{NO}_{3}{ }^{-}$can be explained by the lower free energy of interfacial $\mathrm{NO}_{3}{ }^{-}$than $\mathrm{TFSI}^{-}$(Figure S12), which may result from the geometric shape/size of anions and delocalized intrinsic charge of the cathode (Figures S9A and S9B). However, the $\mathrm{Li}^{+}$ion peak becomes unexpectedly higher, which could be understood by the attraction from accumulated $\mathrm{NO}_{3}{ }^{-}$anions and their strongest interaction with $\mathrm{Li}^{+}$ (Figure S13). At higher electrode polarization $(2.0 \mathrm{~V})$, a similar response is detected for the presence of anions, cations, and DME molecules (Figure S14).

The notable accumulation of $\mathrm{NO}_{3}{ }^{-}$anions and remarkable decrease of DME molecules at the positively polarized $\mathrm{LiCoO}_{2}$ indicate a competition between $\mathrm{NO}_{3}{ }^{-}$entering and $\mathrm{DME}$ leaving from the inner layer of EDL. The accumulation of $\mathrm{NO}_{3}{ }^{-}$anions reduces the number of DME molecules, because the occupation of $\mathrm{NO}_{3}{ }^{-}$ions with their associated $\mathrm{Li}^{+}$ions squeezes out $\mathrm{DME}$ on the cathode (Figures 3A and 3B, and Figure S11). These results provide a qualitative picture: at the cathode surface, the added $\mathrm{NO}_{3}{ }^{-}$anions associated with more $\mathrm{Li}^{+}$ions occupy the space of the inner layer of EDL, minimizing the solvent decomposition, ${ }^{42,44}$ as schematized in Figure 3C and 3D.

To gain deeper insight into the role of added $\mathrm{NO}_{3}^{-}$, we further introduced LiI into these ether electrolytes with and without $\mathrm{NO}_{3}{ }^{-}$(Figure S15A). Adding LiI reduces the oxidation onset potential of pristine ether electrolyte from 3.9 to $2.95 \mathrm{~V}$. As $\mathrm{NO}_{3}{ }^{-}$and $\mathrm{I}^{-}$anions coexist, the onset potential for $\mathrm{I}^{-}$ anions oxidation shifts towards more positive potentials from 2.95 to $3.5 \mathrm{~V}$, confirming competing adsorption between $\mathrm{NO}_{3}{ }^{-}$and $\mathrm{I}^{-}$anions. Nevertheless, the oxidation onset potential is always less than 
$193 \quad 3.9 \mathrm{~V}$ with the presence of $\mathrm{I}^{-}$, suggesting that the easily oxidized $\mathrm{I}^{-}$anions are more likely to contact

194 the cathode surface and dominate interfacial oxidation. This result re-emphasizes the importance of 195 the adsorbate in the oxidation behavior of the electrolyte. Furthermore, by increasing the concentration $196{\text { of } \mathrm{NO}_{3}}^{-}$in the electrolyte (at fixed main salt concentration of $1 \mathrm{M}$ ), the oxidation slowly takes off with 197 its onset potential shifting towards more positive values at higher $\mathrm{NO}_{3}^{-}$content (Figure $\mathrm{S} 15 \mathrm{~B}$ ), 198 providing further evidence for competitive adsorption. The detailed mechanisms are illustrated in 199 Figures S15C-15D. These observations are qualitatively consistent with the anion-adsorption 200 mechanism inferred from MD simulations. Additionally, the adsorbability of $\mathrm{NO}_{3}{ }^{-}$was verified by a 201 steady-state $\mathrm{NO}_{3}{ }^{-}$anion adsorption experiment without external electrode potential, where a lower $202 \mathrm{NO}_{3}{ }^{-}$concentration near the gathered $\mathrm{LiCoO}_{2}$ electrodes can be quantified than in the bulk solution 203 (Note S2 and Figure S16).

204 Altogether, our combined experimental and modeling observations unveil the crucial role of $\mathrm{NO}_{3}{ }^{-}$ 205 -adsorbed interfacial structure on the ether reactivity and provide a picture at the molecular level of 206 the $\mathrm{NO}_{3}{ }^{-}$-anion adsorption behavior at the electrochemical interfaces: that is, the added nitrate would 207 little change the ion solvation in bulk electrolyte but could significantly regulate the EDL structure to 208 inhibit ether oxidative decomposition at the cathode. Meanwhile, it is worth noting that, unlike in the 209 case of super-concentrated aqueous electrolytes, ${ }^{41-43}$ the interfacial chemical signatures in dilute 210 electrolytes do not inherit from the bulk solution.

\section{Cell performances of $\mathrm{LMBs}$ with $\mathrm{NO}_{3}^{-}$-containing ether electrolytes}

212 The highly important merit of high-voltage tolerance brought by adding $\mathrm{NO}_{3}{ }^{-}$in the dilute ether 213 electrolytes can be best signified when testing LMBs with high-loading cathodes. Figure 4 exhibits 214 extremely stable cycling performances of $\mathrm{Li} \|$ cathodes cells consisting of a medium-high cathode areal 215 loading of $1.3-1.4 \mathrm{mAh} \mathrm{cm}^{-2}$ and $\mathrm{NO}_{3}{ }^{-}$-containing dilute ether electrolytes. The $\mathrm{Li} \| \mathrm{LiCoO} 2$ cell in the 216 ether electrolyte with $200 \mathrm{mM} \mathrm{LiNO}_{3}$ showed high capacity retention (95.5\%) (Figure 4A) and a small 217 polarization (Figure S17A) after 300 cycles. Meanwhile, only a trace amount of electrolyte under this 218 condition has been decomposed (maximum mass fraction per cycle $<0.022 \mathrm{wt} \%$, see Note $\mathrm{S} 3 \mathrm{for}$ details). Notably, although this oxidative breakdown did not gradually weaken or halt (Figure S18), it 
220 did not result in continuous undesired cathode capacity fading. Furthermore, this ether electrolyte 221 successfully enabled stable cycling of Li||NMC532 under $4.3 \mathrm{~V}$ for 300 cycles (Figures 4B). To the 222 best of our knowledge, this is the first demonstration that long-term stability of LMB with DME-based 223 ether electrolyte at such low concentration can be obtained under a cutoff voltage of $4.3 \mathrm{~V}$. Admittedly, 224 the reported test conditions still fall short of the stringent requirements of practical LMBs (lean 225 electrolyte, thin $\mathrm{Li}$, and $>3 \mathrm{mAh} \mathrm{cm}^{-2}$ cathode loading). ${ }^{6,24}$. Nevertheless, the effectiveness of our 226 proposed anion-adsorption strategy for increasing the high-voltage tolerance of dilute ether electrolytes 227 is clear from the electrochemical measurements. Further improvements can be gained when $\mathrm{NO}_{3}{ }^{-}-$ 228 containing ether electrolytes are used in combination with other strategies for Li metal stabilization, 229 such as nanostructuring the electrode ${ }^{11}$ and coordinating different salts $^{17}$.

\section{Generality of strategy}

231 To assess the generality of this nitrate additive strategy, different types of main salts and ether 232 electrolyte systems were chosen. The lithium bis(fluorosulfonyl)imide (LiFSI)-based dilute 233 electrolytes with $\mathrm{NO}_{3}{ }^{-}$showed good compatibility with $\mathrm{LiCoO}_{2}$ and $\mathrm{NMC532}$ cathodes under a cutoff 234 voltage of $4.3 \mathrm{~V}$, realizing high capacity retentions of $94.2 \%$ and $90.4 \%$, respectively, for over 600 cycles (Figure S19). More importantly, high-voltage tolerance of $4.3 \mathrm{~V}$ was also confirmed in the sodium (Na)-ion electrolyte system (Figure S20). 1000-cycle Na-ion battery with Na Prussian blue (NaPB) was achieved in $1 \mathrm{M} \mathrm{NaPF}_{6} \mathrm{DME}_{\text {with }} 50 \mathrm{mM} \mathrm{NaNO}_{3}$. These results illustrate the feasibility of our strategy by adding tiny $\mathrm{NO}_{3}{ }^{-}$to increase the high-voltage tolerance of dilute ether electrolytes.

Beyond the nitrate, are there more additives? Could rational criteria be proposed for identifying appropriate additives? To answer these questions, we carried out a number of electrochemical experiments to employ a series of inorganic salts as additives to alter the ether solvent environment in EDLs (see Table S1 for detailed classification of salts). Considering that involvement of $\mathrm{I}^{-}$hampers the packing of the $\mathrm{NO}_{3}{ }^{-}$adsorption layer (Figure $\mathrm{S} 15 \mathrm{~A}$ ), the oxidation tolerance of the anion itself is taken into account first; for instance, oxidation of $\mathrm{N}$ (III) in $\mathrm{NO}_{2}^{-}$rather than $\mathrm{N}$ (VI) in $\mathrm{NO}_{3}^{-}$is favored thermodynamically. As shown in Figures S22A and S22C, the LSV for $\mathrm{NaNO}_{2}$-containing ether electrolyte exhibited a weak current response early at $\sim 3.9 \mathrm{~V}$, with two new oxidation peaks appearing 
at high potentials. The detailed investigation suggests that the irreversible oxidation of $\mathrm{NaNO}_{2}$ salt accounts for the appearance of these peaks (Figures S22D and S22E). Even though the overall onset of oxidation of this $\mathrm{NaNO}_{2}$-containing ether electrolyte becomes $\sim 0.2 \mathrm{~V}$ higher than in the presence of $\mathrm{LiNO}_{3}$ (Figure S22A), further attempts to test the cycling stability of this electrolyte in $\mathrm{Li} \| \mathrm{LiCoO} 2$ proved fruitless (Figure S22B). Meanwhile, better oxidation stability of $\mathrm{LiClO}_{4}$ than $\mathrm{NaClO}_{3}$ was experimentally confirmed by a higher onset potential of oxidation in the $\mathrm{LiClO}_{4}$-containing ether electrolytes (Figure S23). As for the $\mathrm{Na}_{2} \mathrm{SO}_{4}$ with $\mathrm{S}$ (VI) and $\mathrm{AlPO}_{4}$ with $\mathrm{P}$ (V) (two types of soluble/slightly soluble salts with high valence state, Table S1), they failed to enhance the oxidation stability of the ether electrolytes. But interestingly, $\mathrm{KH}_{2} \mathrm{PO}_{4}$ and $\mathrm{K}_{2} \mathrm{HPO}_{4}$ with $\mathrm{P}(\mathrm{V})$ enabled improved oxidation tolerance of the dilute ether electrolytes (Figure S24). Finally, except for the undissolved salts in ethers, the oxidation stability was experimentally found to increase with the presence of five salts, including $\mathrm{LiNO}_{3}, \mathrm{LiClO}_{4}, \mathrm{NaClO}_{3}, \mathrm{KH}_{2} \mathrm{PO}_{4}$ and $\mathrm{K}_{2} \mathrm{HPO}_{4}$, where the maximum enhancement was obtained when $\mathrm{LiClO}_{4}$ salt was used (Table S1).

To delve into the difference of these resultful additives, a plot of the onset shift as a function of corresponding anion radius is shown in Figure 5 (see Figure S21 for the confirmation of onset potential). A nearly linear decrease of the onset shift with increased anion radius highlights the importance of ion size in adsorption. As for the abnormal trend of $\mathrm{LiClO}_{4}$, specific adsorption (normally occurs in the $\mathrm{IHP}^{45}$ ) rather than electro-adsorption may account for its interfacial as well as electrochemical behavior. Combined with results of competitive adsorption in the presence of LiI, we can therefore reach four requirements for additive selection/design that should be simultaneously met: (1) certain solubility in ether electrolytes, (2) high oxidation stability of anions, (3) strong specific adsorption/electro-adsorption ability with (4) small geometric size for lowering the steric barrier.

\section{Conclusion}

We have developed dilute ether electrolytes by adding a small amount of $\mathrm{NO}_{3}{ }^{-}$anions for long-term cycling of LMBs under voltages as high as $4.3 \mathrm{~V}$, which break the long-standing voltage limitation for dilute ether electrolytes. Our combined experimental and modeling results have uncovered that accumulation of added $\mathrm{NO}_{3}{ }^{-}$in the inner layer of EDL at the cathode is important to squeeze out DME 
274 molecules at the cathode and thus suppresses the ether reactivity.

275 This study reveals new surface chemistry in the dilute ether electrolyte - surface adsorbates matter 276 to alter the solvent environment at a polarized cathode. This picture is qualitatively different from the 277 high-/super-concentrated electrolytes, where their interfacial features inherit chemical signatures from 278 bulk solution, namely, anions instead of solvent molecules dominated; ${ }^{40-43}$ while the interfacial 279 chemistry of dilute electrolytes with additives in this study is primarily dominated by the oxidation of 280 solvent molecules. ${ }^{15}$ Therefore, in the presence of additives, the purely anion-adsorption mechanism 281 should start to become primary, highlighting the crucial role of anion-regulated interfacial feature 282 rather than the nature of bulk solution on the solvent stability in the electrochemical device using dilute 283 electrolytes.

284 Our findings point to the value of regulating the surface adsorbates at the cathode to control the 285 interfacial nanostructure and consequently the solvent reactivity. This paves a new way for designing 286 "adsorption-type" additives for high-voltage dilute ethers, since there are a huge number of possible 287 surface adsorbates that can be employed to fine-tune the interfacial nanostructure and hence control 288 interfacial electrochemical reactivity. This acquired knowledge extends the understanding of dilute 289 electrolytes and their design, which could be used for a wide variety of electrochemical devices for 290 improved safety (for instance, dendrite suppression in $\mathrm{Zn}$ batteries ${ }^{46}$ ), controllable reactivity (for 291 instance, enhanced oxygen reduction ${ }^{32}$ or weakened water reduction ${ }^{47}$ ), or increased selectivity (for 292 instance, $\mathrm{CO}_{2}$ reduction $^{48}$ ). 
294 Electrolyte and electrode preparation. LiFSI was purchased from Fluolyte and Smooth Way; LiTFSI, LiPF, $295 \mathrm{NaPF}_{6}, \mathrm{MgSO}_{4}, \mathrm{Na}_{2} \mathrm{SO}_{4}, \mathrm{NaHSO}_{3}, \mathrm{NaClO}_{3}, \mathrm{KH}_{2} \mathrm{PO}_{4}, \mathrm{NaNO}_{2}, \mathrm{NaNO}_{3}$, DME, and diethylene glycol dimethyl 296 ether (G2) were purchased from Sigma-Aldrich; $\mathrm{LiNO}_{3}$ and $\mathrm{AlPO}_{4}$ were purchased from Alfa Aesar; LiI and $\mathrm{LiClO}_{4}$ were purchased from Aladdin; LiOTf and $\mathrm{LiBF}_{4}$ were purchased from TCI; $\mathrm{LiPO}_{3}$ and $\mathrm{Li}_{3} \mathrm{PO}_{4}$ were purchased from Energy Chemical; $\mathrm{K}_{2} \mathrm{HPO}_{4}$ was purchased from Acros. DME and G2 solvents were dried over $4 \AA$ molecular sieves (Sigma-Aldrich) prior to preparing electrolytes. The electrolytes were prepared by dissolving the selected (mixture) salts in the DME/G2 solvent in an argon gas-filled glove box (MBraun) with oxygen and moisture contents below $0.1 \mathrm{ppm}$.

$\mathrm{LiCoO}_{2}$ and $\mathrm{LiNi}_{0.5} \mathrm{Mn}_{0.3} \mathrm{Co}_{0.2} \mathrm{O}_{2}$ ( $\mathrm{NMC532}$ ) cathode materials were purchased from Canrd and used as received. The laminate of low/medium-high loading $\mathrm{LiCoO}_{2}$ electrodes $\left(\sim 1.9 / \sim 9.3 \mathrm{mg}\right.$ active material $\left.\mathrm{cm}^{-2}\right)$ and NMC532 electrodes $\left(\sim 1.9 / \sim 9.8 \mathrm{mg}\right.$ active material $\left.\mathrm{cm}^{-2}\right)$ were prepared by casting a slurry mixture containing $90 \mathrm{wt} \%$ active material, $5 \mathrm{wt} \%$ carbon black (Super P, Canrd) and $5 \mathrm{wt} \%$ polyvinylidene difluoride (PVdF, Canrd) in N-methylpyrrolidone onto an aluminum (Al) foil. After drying at $110{ }^{\circ} \mathrm{C}$ under vacuum for $12 \mathrm{~h}$, the electrodes were cut into discs with a diameter of $12 \mathrm{~mm}$. Thick Li foil (450 $\mu \mathrm{m}$ thickness, $1.56 \mathrm{~cm}$ diameter) was purchased from MTI. NaPB was synthesized following a previous report ${ }^{49}$. The areal mass loading of $\mathrm{NaPB}$ in the electrode was $\sim 1 \mathrm{mg} \mathrm{cm}^{-2}$.

Electrochemical measurements. $\mathrm{Li} \| \mathrm{LiCoO}_{2}$ and $\mathrm{Li}|| \mathrm{NMC} 532$ cells were assembled in the standard CR2032 coin-type cells, with thick Li foil $(450 \mu \mathrm{m})$ as the anode, one-piece separator (Celgard2400) separator and the prepared electrolyte $\left(70 \mu \mathrm{L}\right.$ in each cell). The $\mathrm{Li} \| \mathrm{LiCoO}_{2}$ and $\mathrm{Li} \| \mathrm{NMC} 532$ cells were tested in constant-current mode on battery testers (Wuhan LAND) within the voltage range of 3.0-4.3 V and 2.8-4.3 V, respectively. Only for the Li||NMC532 cells with medium-high loading electrodes, a constant-current-constant-voltage mode was used; cells were charged to $4.3 \mathrm{~V}$ and then held at $4.3 \mathrm{~V}$ until the charge current decayed to $\mathrm{C} / 10$, where $1 \mathrm{C}$ is equal to $180 \mathrm{~mA} \mathrm{~g}^{-1}$. LSV studies of the electrolytes were conducted on a Biologic VMP3 system. Electrochemical impedance spectroscopy (EIS) was conducted in a three-electrode cell (ECC-ref cell (ELCELL)) configuration using a Solartron 1470E workstation.

Characterizations. Morphological characterization was performed using optical microscopy (Carl Zeiss Microscopy, Germany), SEM (HITACHI SU8010, Japan), and high-resolution TEM (FEI Tecnai G2 F30, USA). ${ }^{17} \mathrm{O}$ NMR data were obtained on a Bruker Avance $400 \mathrm{MHz}$ NMR spectrometer. $400 \mu \mathrm{L}$ electrolyte was put into $5 \mathrm{~mm}$ NMR tube with $150 \mu \mathrm{L}$ deuterium oxide $\left(\mathrm{D}_{2} \mathrm{O}\right)$ as an external reference in a coaxal insert tube (NORELL). XPS analysis was obtained on a PHI 5000 VersaProbe II spectrometer using monochromatic A1 Ka X-ray source. Before conducting SEM, TEM, and XPS studies of cycled electrodes, cells were disassembled in the glovebox, and the obtained electrodes were rinsed with DME to remove residue salts. The cross-sections of Li anodes were obtained by cutting the Li foils with a razor blade. Air-free transfer vessels were used to avoid any contamination from the air. Ultraviolet-visible spectrophotometer (UV-vis, Agilent Cary5000, USA) was used to quantify the concentration of $\mathrm{NO}_{3}{ }^{-}$based on its absorbance at $297 \mathrm{~nm}$.

Molecular dynamics simulation. Molecular dynamics simulations were performed to investigate the molecular structure of bulk and interfacial region on the cathode, using MD package GROMACS ${ }^{50}$. The schematic of system are shown in Figures S8A and S8B. For the electrode-electrolyte system, the constant potential method was implemented ${ }^{39}$ in GROMACS and further developed for asymmetric electrode systems. The force field for 
333 the electrolyte is developed by Dzubiella et al. ${ }^{51}$, which can satisfactorily reproduce density, dielectric constant, 334 viscosity, and diffusion coefficient of $\mathrm{LiTFSI} / \mathrm{LiNO}_{3} / \mathrm{DME} / \mathrm{DOL}$ mixtures measured by experiments. The 335 parameters for the van-der-Waals potential of $\mathrm{LiCoO}_{2}$ cathode are taken from the UFF force field ${ }^{52}$, and those 336 for Li metal anode are taken from $\mathrm{ref}^{53}$. While the structure and intrinsic charge of Li metal anode and $\mathrm{LiCoO}_{2}$ 337 cathode are optimized using the density functional theory (DFT) with results shown in Figure S9. The details 338 for simulations are presented in Note S1.

\section{ACKNOWLEDGEMENTS}

340 We acknowledge funding support from the National Natural Science Foundation of China (nos. 51772167, 341 52072206, and 52161135104), Local Innovative and Research Teams Project of Guangdong Pearl River Talents 342 Program (no. 2017BT01N111), Shenzhen Stable Supporting Project (no. WDZC20200818155913001), and 343 Hubei Provincial Natural Science Foundation of China (no. 2020CFA093). H.W. thanks Dr. K. Zhou and J. 344 Dong for preparing/synthesizing cathode materials. The work at HUST is also supported by the Program for 345 HUST Academic Frontier Youth Team.

\section{AUTHOR CONTRIBUTIONS}

347 H.W. conceived the idea and designed the experiments; G.F. designed the modeling. D.Z. and F.K. directed the 348 project. H.W. performed SEM experiments, electrochemical measurements, and coin-cell tests. H.Z. and W.L. 349 performed the XPS measurements, collected the ${ }^{17} \mathrm{O}-\mathrm{NMR}$ spectra and ultraviolet-visible spectra. J.Z. and L.Z. 350 performed MD simulations. M.C., Q.G., and K.C.L. performed DFT simulations. H.W., J.Z., and G.F. wrote the 351 manuscript. All authors contributed to discussing data, editing, and revising the paper.

\section{DECLARATION OF INTERESTS}

353 The authors declare no competing interests. 


\section{REFERENCES}

1. Armand, M., and Tarascon, J.M. (2008). Building better batteries. Nature 451, 652-657.

2. Dunn, B., Kamath, H., and Tarascon, J.-M. (2011). Electrical energy storage for the grid: a battery of choices. Science 334, 928-935.

3. Croce, F., Appetecchi, G.B., Persi, L., and Scrosati, B. (1998). Nanocomposite polymer electrolytes for lithium batteries. Nature 394, 456-458.

4. Dixit, M.B., Zaman, W., Hortance, N., Vujic, S., Harkey, B., Shen, F., Tsai, W.-Y., De Andrade, V., Chen, X.C., Balke, N., and Hatzell, K.B. (2020). Nanoscale mapping of extrinsic interfaces in hybrid solid electrolytes. Joule 4, 207-221.

5. Armand, M., Endres, F., MacFarlane, D.R., Ohno, H., and Scrosati, B. (2009). Ionic-liquid materials for the electrochemical challenges of the future. Nat. Mater. 8, 621-629.

6. Liu, J., Bao, Z., Cui, Y., Dufek, E.J., Goodenough, J.B., Khalifah, P., Li, Q., Liaw, B.Y., Liu, P., Manthiram, A., et al. (2019). Pathways for practical high-energy long-cycling lithium metal batteries. Nat. Energy 4, 180-186.

7. Zhao, Q., Stalin, S., and Archer, L.A. (2021). Stabilizing metal battery anodes through the design of solid electrolyte interphases. Joule 5, 1119-1142.

8. Xu, K. (2014). Electrolytes and interphases in Li-ion batteries and beyond. Chem. Rev. 114, 11503-11618.

9. Lin, D., Liu, Y., and Cui, Y. (2017). Reviving the lithium metal anode for high-energy batteries. Nat. Nanotechnol. 12, 194-206.

10. Heiskanen, S.K., Kim, J., and Lucht, B.L. (2019). Generation and evolution of the solid electrolyte interphase of lithium-ion batteries. Joule 3, 2322-2333.

11. Lin, D., Liu, Y., Liang, Z., Lee, H.-W., Sun, J., Wang, H., Yan, K., Xie, J., and Cui, Y. (2016). Layered reduced graphene oxide with nanoscale interlayer gaps as a stable host for lithium metal anodes. Nat. Nanotechnol. 11, 626-632.

12. Qian, J., Henderson, W.A., Xu, W., Bhattacharya, P., Engelhard, M., Borodin, O., and Zhang, J.-G. (2015). High rate and stable cycling of lithium metal anode. Nat. Commun. 6, 6362.

13. Cao, X., Ren, X., Zou, L., Engelhard, M.H., Huang, W., Wang, H., Matthews, B.E., Lee, H., Niu, C., Arey, B.W., et al. (2019). Monolithic solid-electrolyte interphases formed in fluorinated orthoformate-based electrolytes minimize Li depletion and pulverization. Nat. Energy 4, 796-805.

14. Jiao, S., Ren, X., Cao, R., Engelhard, M.H., Liu, Y., Hu, D., Mei, D., Zheng, J., Zhao, W., Li, Q., et al. (2018). Stable cycling of high-voltage lithium metal batteries in ether electrolytes. Nat. Energy 3, 739-746.

15. Borodin, O., Self, J., Persson, K.A., Wang, C., and Xu, K. (2020). Uncharted waters: super-concentrated electrolytes. Joule 4, 69-100.

16. Yamada, Y., Wang, J., Ko, S., Watanabe, E., and Yamada, A. (2019). Advances and issues in developing salt-concentrated battery electrolytes. Nat. Energy 4, 269-280.

17. Qiu, F., Li, X., Deng, H., Wang, D., Mu, X., He, P., and Zhou, H. (2019). A concentrated ternary-salts electrolyte for high reversible Li metal battery with slight excess Li. Adv. Energy Mater. 9, 1803372.

18. Zhang, S.S. (2012). Role of $\mathrm{LiNO}_{3}$ in rechargeable lithium/sulfur battery. Electrochim. Acta 70, 344-348.

19. Fan, X., and Wang, C. (2021). High-voltage liquid electrolytes for Li batteries: progress and perspectives. Chem. Soc. Rev. 50, 10486-10566.

20. Yoshida, K., Nakamura, M., Kazue, Y., Tachikawa, N., Tsuzuki, S., Seki, S., Dokko, K., and Watanabe, M. (2011). Oxidative-stability enhancement and charge transport mechanism in glyme-lithium salt equimolar 
complexes. J. Am. Chem. Soc. 133, 13121-13129.

21. Ren, X., Zou, L., Jiao, S., Mei, D., Engelhard, M.H., Li, Q., Lee, H., Niu, C., Adams, B.D., Wang, C., et al. (2019). High-concentration ether electrolytes for stable high-voltage lithium metal batteries. ACS Energy Lett. 4, 896-902.

22. Alvarado, J., Schroeder, M.A., Pollard, T.P., Wang, X., Lee, J.Z., Zhang, M., Wynn, T., Ding, M., Borodin, O., Meng, Y.S., and Xu, K. (2019). Bisalt ether electrolytes: a pathway towards lithium metal batteries with Ni-rich cathodes. Energy Environ. Sci. 12, 780-794.

23. Ren, X., Zou, L., Cao, X., Engelhard, M.H., Liu, W., Burton, S.D., Lee, H., Niu, C., Matthews, B.E., Zhu, Z., et al. (2019). Enabling high-voltage lithium-metal batteries under practical conditions. Joule 3, 16621676.

24. Niu, C., Liu, D., Lochala, J.A., Anderson, C.S., Cao, X., Gross, M.E., Xu, W., Zhang, J.-G., Whittingham, M.S., Xiao, J., and Liu, J. (2021). Balancing interfacial reactions to achieve long cycle life in high-energy lithium metal batteries. Nat. Energy 6, 723-732.

25. Tsai, W.T. (2005). Environmental risk assessment of hydrofluoroethers (HFEs). J. Hazard. Mater. 119, 6978.

26. Amanchukwu, C.V., Yu, Z., Kong, X., Qin, J., Cui, Y., and Bao, Z. (2020). A new class of ionically conducting fluorinated ether electrolytes with high electrochemical stability. J. Am. Chem. Soc. 142, 73937403.

27. Yu, Z., Wang, H., Kong, X., Huang, W., Tsao, Y., Mackanic, D.G., Wang, K., Wang, X., Huang, W., Choudhury, S., et al. (2020). Molecular design for electrolyte solvents enabling energy-dense and longcycling lithium metal batteries. Nat. Energy 5, 526-533.

28. Zhang, X.-Q., Chen, X., Hou, L.-P., Li, B.-Q., Cheng, X.-B., Huang, J.-Q., and Zhang, Q. (2019). Regulating anions in the solvation sheath of lithium ions for stable lithium metal batteries. ACS Energy Lett. 4, 411-416.

29. Liu, Y., Lin, D., Li, Y., Chen, G., Pei, A., Nix, O., Li, Y., and Cui, Y. (2018). Solubility-mediated sustained release enabling nitrate additive in carbonate electrolytes for stable lithium metal anode. Nat. Commun. 9, 3656.

30. Shi, F., Pei, A., Vailionis, A., Xie, J., Liu, B., Zhao, J., Gong, Y., and Cui, Y. (2017). Strong texturing of lithium metal in batteries. Proc. Natl Acad. Sci. USA 114, 12138-12143.

31. Yan, C., Li, H.-R., Chen, X., Zhang, X.-Q., Cheng, X.-B., Xu, R., Huang, J.-Q., and Zhang, Q. (2019). Regulating the inner helmholtz plane for stable solid electrolyte interphase on lithium metal anodes. J. Am. Chem. Soc. 141, 9422-9429.

32. Wang, T., Zhang, Y., Huang, B., Cai, B., Rao, R.R., Giordano, L., Sun, S.-G., and Shao-Horn, Y. (2021). Enhancing oxygen reduction electrocatalysis by tuning interfacial hydrogen bonds. Nat. Catal. 4, 753-762.

33. Holloczki, O., Macchieraldo, R., Gleede, B., Waldvogel, S.R., and Kirchner, B. (2019). Interfacial domain formation enhances electrochemical synthesis. J. Phys. Chem. Lett. 10, 1192-1197.

34. Huang, C.-J., Thirumalraj, B., Tao, H.-C., Shitaw, K.N., Sutiono, H., Hagos, T.T., Beyene, T.T., Kuo, L.M., Wang, C.-C., Wu, S.-H., et al. (2021). Decoupling the origins of irreversible coulombic efficiency in anode-free lithium metal batteries. Nat. Commun. 12, 1452.

35. Gauthier, M., Karayaylali, P., Giordano, L., Feng, S., Lux, S.F., Maglia, F., Lamp, P., and Shao-Horn, Y. (2018). Probing surface chemistry changes using $\mathrm{LiCoO}_{2}$-only electrodes in Li-ion batteries. J. Electrochem. Soc. 165, A1377-A1387. 
36. Zhang, J.-N., Li, Q., Ouyang, C., Yu, X., Ge, M., Huang, X., Hu, E., Ma, C., Li, S., Xiao, R., et al. (2019). Trace doping of multiple elements enables stable battery cycling of $\mathrm{LiCoO}_{2}$ at $4.6 \mathrm{~V}$. Nat. Energy 4, 594603.

37. Mao, X.W., Brown, P., Cervinka, C., Hazell, G., Li, H., Ren, Y.Y., Chen, D., Atkin, R., Eastoe, J., Grillo, I., et al. (2019). Self-assembled nanostructures in ionic liquids facilitate charge storage at electrified interfaces. Nat. Mater. 18, 1350-1357.

38. Rakov, D.A., Chen, F.F., Ferdousi, S.A., Li, H., Pathirana, T., Simonov, A.N., Howlett, P.C., Atkin, R., and Forsyth, M. (2020). Engineering high-energy-density sodium battery anodes for improved cycling with superconcentrated ionic-liquid electrolytes. Nat. Mater. 19, 1096-1101.

39. Bi, S., Banda, H., Chen, M., Niu, L., Chen, M., Wu, T., Wang, J., Wang, R., Feng, J., Chen, T., et al. (2020). Molecular understanding of charge storage and charging dynamics in supercapacitors with MOF electrodes and ionic liquid electrolytes. Nat. Mater. 19, 552-558.

40. McOwen, D.W., Seo, D.M., Borodin, O., Vatamanu, J., Boyle, P.D., and Henderson, W.A. (2014). Concentrated electrolytes: decrypting electrolyte properties and reassessing Al corrosion mechanisms. Energy Environ. Sci. 7, 416-426.

41. Wang, F., Borodin, O., Ding, M.S., Gobet, M., Vatamanu, J., Fan, X., Gao, T., Edison, N., Liang, Y., Sun, W., et al. (2018). Hybrid aqueous/non-aqueous electrolyte for safe and high-energy Li-ion batteries. Joule 2, 927-937.

42. Yang, C., Chen, J., Qing, T., Fan, X., Sun, W., von Cresce, A., Ding, M.S., Borodin, O., Vatamanu, J., Schroeder, M.A., et al. (2017). 4.0 V aqueous Li-ion batteries. Joule 1, 122-132.

43. Suo, L., Borodin, O., Gao, T., Olguin, M., Ho, J., Fan, X., Luo, C., Wang, C., and Xu, K. (2015). "Waterin-salt" electrolyte enables high-voltage aqueous lithium-ion chemistries. Science 350, 938-943.

44. Sun, W., Wang, F., Zhang, B., Zhang, M., Kuepers, V., Ji, X., Theile, C., Bieker, P., Xu, K., Wang, C., and Winter, M. (2021). A rechargeable zinc-air battery based on zinc peroxide chemistry. Science 371, 46-51.

45. Wang, X., Salari, M., Jiang, D.-e., Chapman Varela, J., Anasori, B., Wesolowski, D.J., Dai, S., Grinstaff, M.W., and Gogotsi, Y. (2020). Electrode material-ionic liquid coupling for electrochemical energy storage. Nat. Rev. Mater. 5, 787-808.

46. Bayaguud, A., Luo, X., Fu, Y., and Zhu, C. (2020). Cationic surfactant-type electrolyte additive enables three-dimensional dendrite-free zinc anode for stable zinc-ion batteries. ACS Energy Lett. 5, 3012-3020.

47. Dubouis, N., Serva, A., Berthin, R., Jeanmairet, G., Porcheron, B., Salager, E., Salanne, M., and Grimaud, A. (2020). Tuning water reduction through controlled nanoconfinement within an organic liquid matrix. Nat. Catal. 3, 656-663.

48. Wagner, A., Sahm, C.D., and Reisner, E. (2020). Towards molecular understanding of local chemical environment effects in electro- and photocatalytic $\mathrm{CO}_{2}$ reduction. Nat. Catal. 3, 775-786.

49. You, Y., Yu, X., Yin, Y., Nam, K.-W., and Guo, Y.-G. (2015). Sodium iron hexacyanoferrate with high Na content as a Na-rich cathode material for Na-ion batteries. Nano Res. 8, 117-128.

50. Van Der Spoel, D., Lindahl, E., Hess, B., Groenhof, G., Mark, A.E., and Berendsen, H.J.C. (2005). GROMACS: Fast, flexible, and free. J Comput Chem 26, 1701-1718.

51. Park, C., Kanduc, M., Chudoba, R., Ronneburg, A., Risse, S., Ballauff, M., and Dzubiella, J. (2018). Molecular simulations of electrolyte structure and dynamics in lithium-sulfur battery solvents. J. Power Sources 373, 70-78.

52. Rappé, A.K., Casewit, C., Colwell, K.S., Goddard, W.A., and Skiff, W.M. (1992). UFF, a full periodic table 
force field for molecular mechanics and molecular dynamics simulations. J. Am. Chem. Soc. 114, 1002410035.

483 53. Ebadi, M., Costa, L.T., Araujo, C.M., and Brandell, D. (2017). modelling the polymer electrolyte/li-metal interface by molecular dynamics simulations. Electrochim. Acta 234, 43-51. 
A

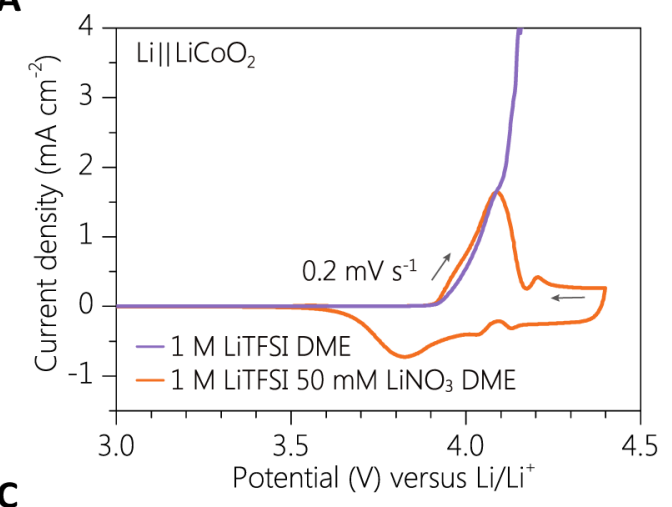

B

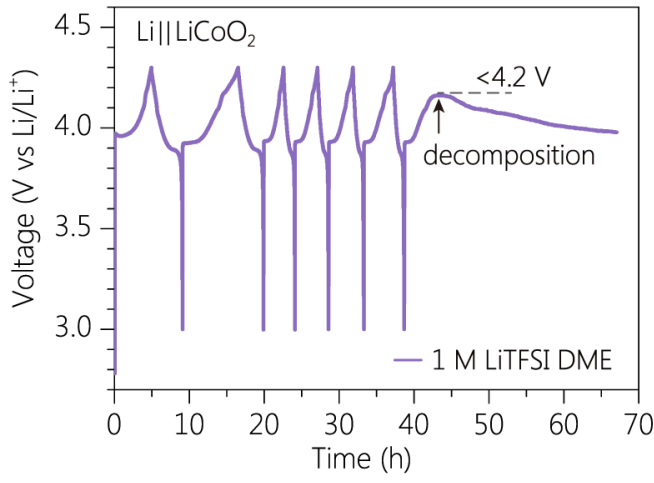

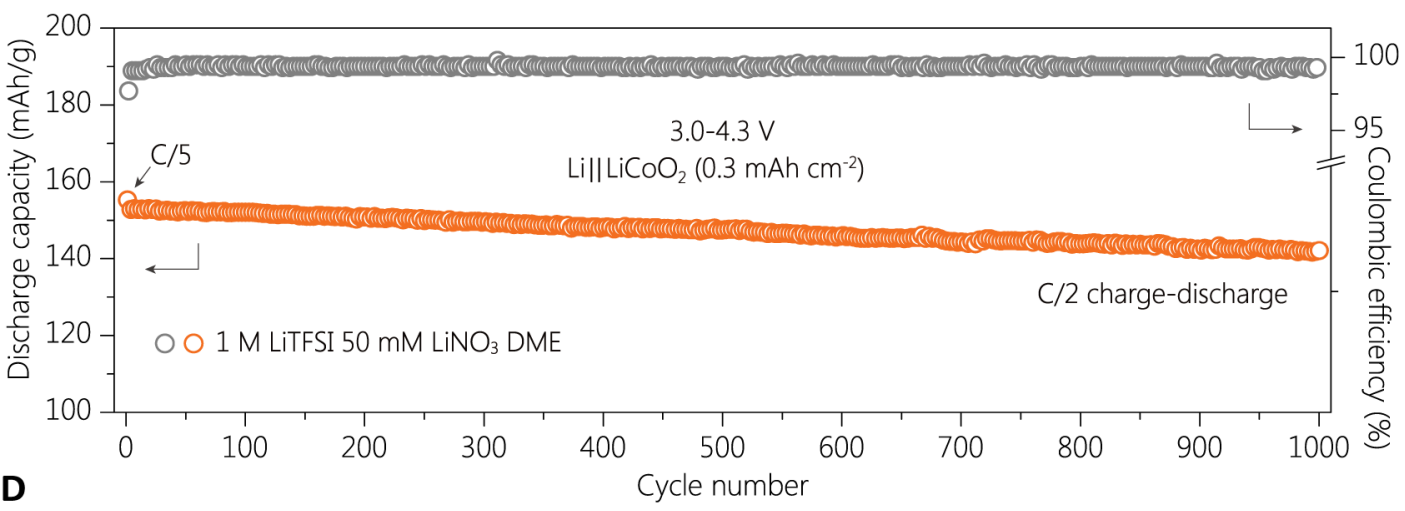

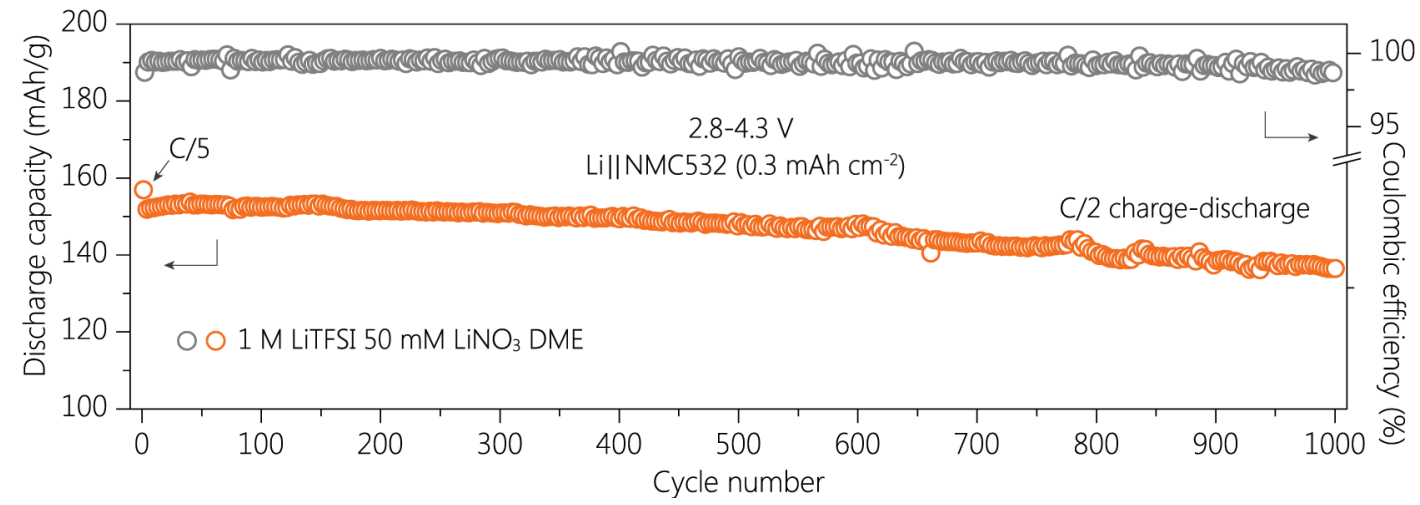

487 Figure 1. Electrochemical behavior of ether electrolytes in $\mathrm{Li} \| \mathrm{LiCoO}_{2}$ and $\mathrm{Li} \| \mathrm{NMC532}$ batteries.

488 (A) $\mathrm{CV}$ curves of the $\mathrm{NO}_{3}{ }^{-}$-containing and $\mathrm{NO}_{3}{ }^{-}$-free dilute ether electrolytes with $\mathrm{LiCoO}_{2}$ cathodes as working 489 electrodes in $\mathrm{Li}|| \mathrm{LiCoO}_{2}$ coin cells. (B) Voltage profile of $\mathrm{Li}|| \mathrm{LiCoO}_{2}$ coin cell with $1 \mathrm{M}$ LiTFSI DME.

490 (C and D) Cycling performance of (C) $\mathrm{Li}_{\mid} \mid \mathrm{LiCoO}_{2}$ and (D) $\mathrm{Li}|| \mathrm{NMC} 532$ batteries in the $\mathrm{NO}_{3}{ }^{-}$-containing dilute 491 ether electrolyte under $4.3 \mathrm{~V}$ charge cutoff voltage. 
A

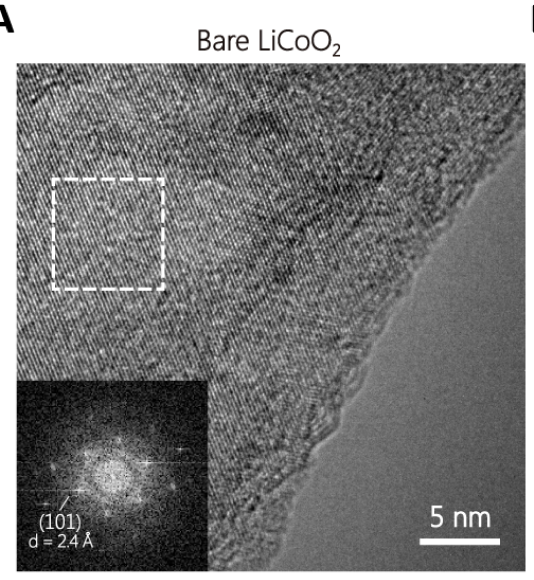

C

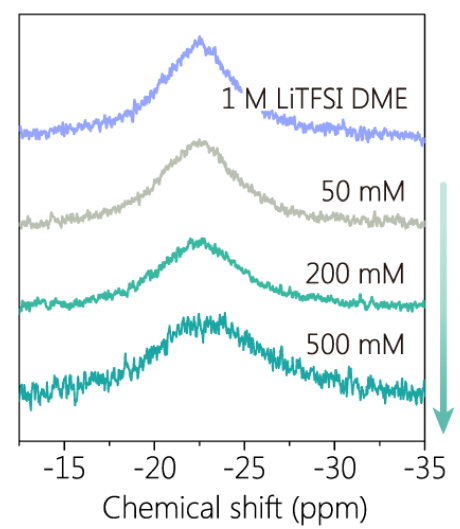

E

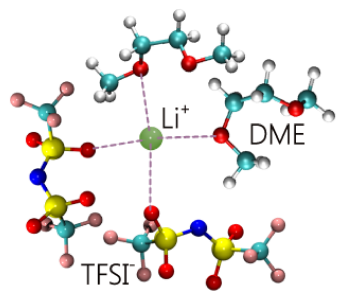

1 M LITFSI DME
B

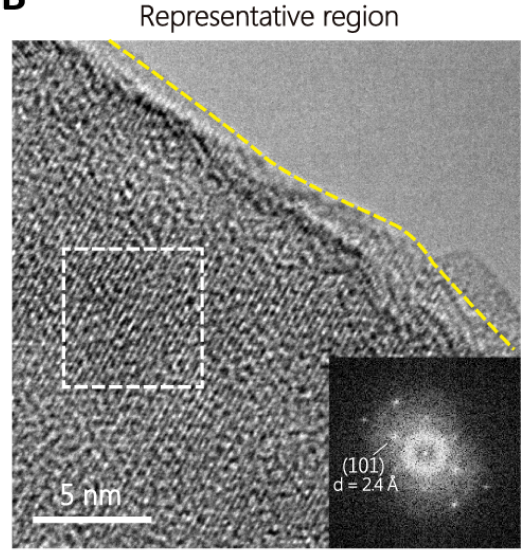

D

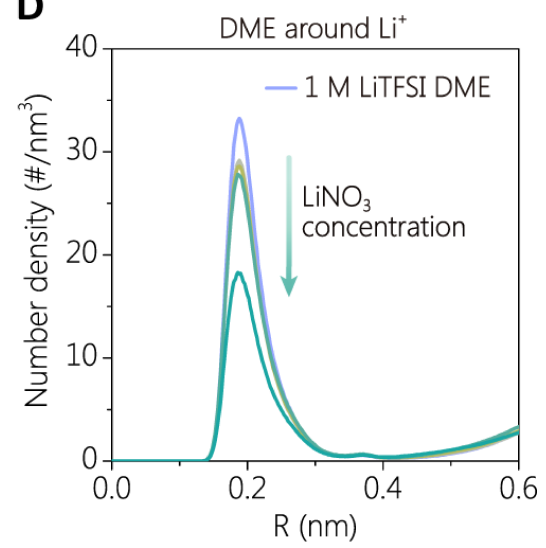

G
F

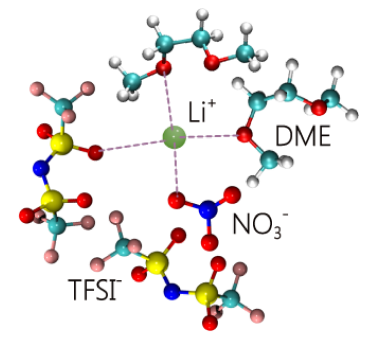

1 M LiTFSI DME with $50 \mathrm{mM} \mathrm{LiNO}_{3}$

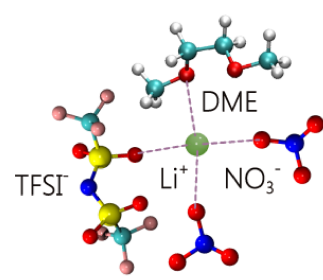

1 M LiTFSI DME with $500 \mathrm{mM} \mathrm{LiNO}_{3}$

493 Figure 2. Analysis of the electrolyte decomposition and solvation structure in the presence of nitrate.

494 (A and B) TEM images of (A) bare $\mathrm{LiCoO}_{2}$, (B) representative region of cycled $\mathrm{LiCoO}_{2}$ electrode (50 cycles) 495 under charge cutoff voltage of $4.3 \mathrm{~V}$ in $1 \mathrm{M}$ LiTFSI $50 \mathrm{mM} \mathrm{LiNO}_{3} \mathrm{DME}$ electrolyte. Insets are the fast Fourier 496 transform (FFT) patterns of selected regions.

497 (C and D) (C) ${ }^{17} \mathrm{O}-\mathrm{NMR}$ and (D) radial number density of DME around $\mathrm{Li}^{+}$of $1 \mathrm{M}$ LiTFSI DME electrolyte 498 (top blue) and $1 \mathrm{M}$ LiTFSI DME with increasing $\mathrm{LiNO}_{3}$ concentration (bottom green).

499 (E-G) Solvation structure of (E) 1 M LiTFSI DME, (F) 1 M LiTFSI DME with $50 \mathrm{mM} \mathrm{LiNO}_{3}$, and (G) $1 \mathrm{M}$

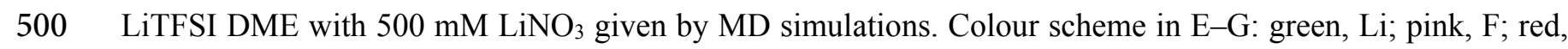
501 O; light blue, C; navy, N; yellow, S; silver gray, H. 
A

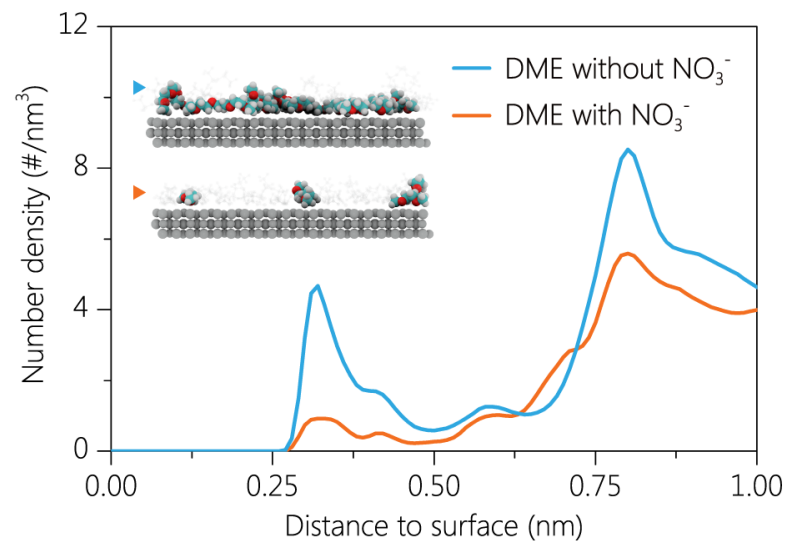

C

Conventional dilute DME electrolyte
B

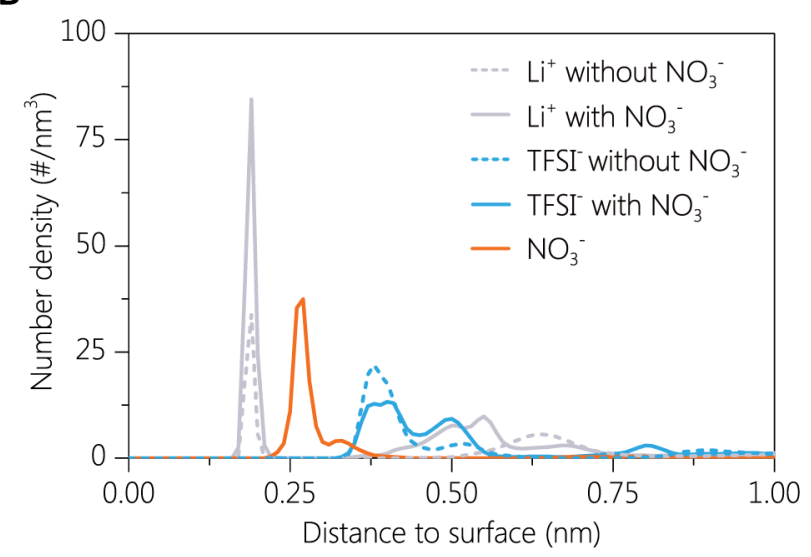

D

Dilute DME electrolyte with $\mathrm{NO}_{3}{ }^{-}$anion
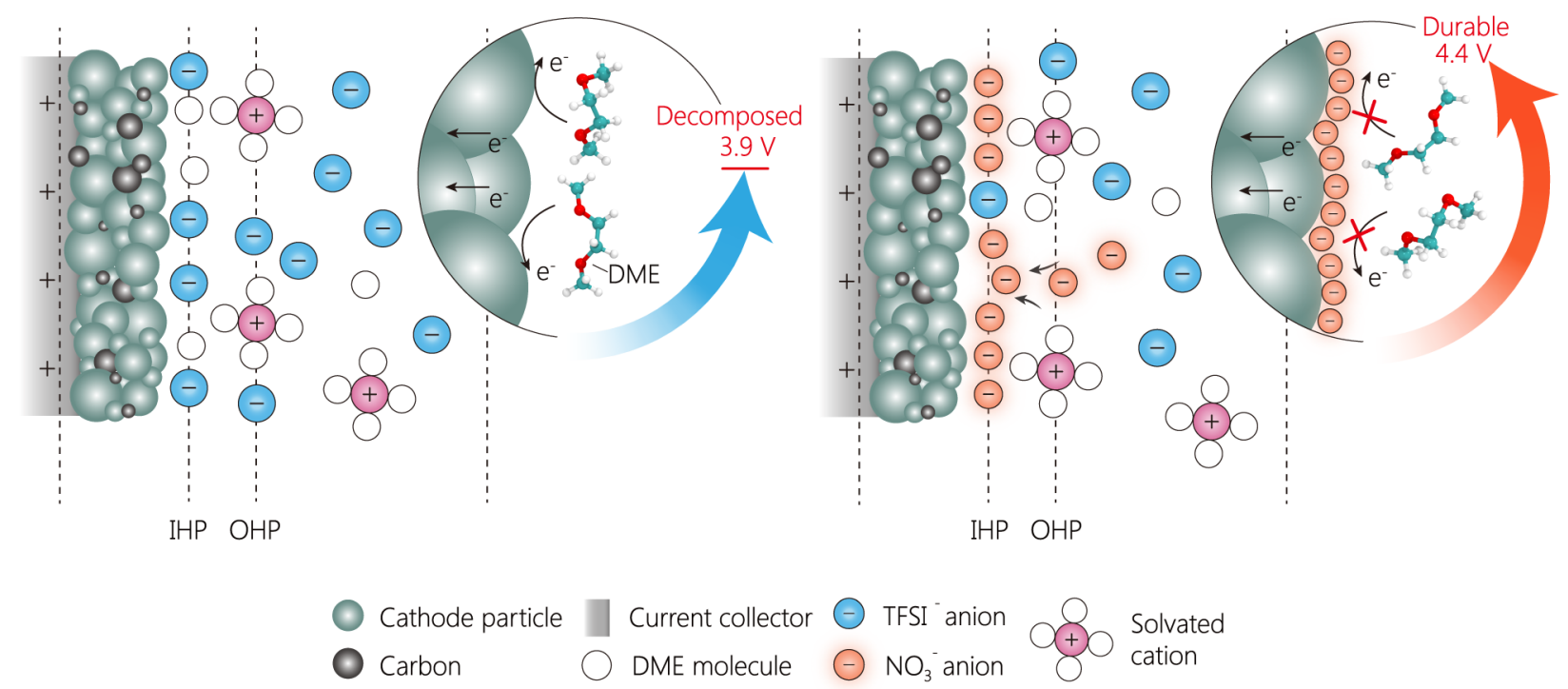

Solvated cation

504 Figure 3. Ion and DME distributions at electrified $\mathrm{LiCoO}_{2}$ interfaces and their effect on DME decomposition.

506 (A and B) The number density along with the distance from the surface of $\mathrm{LiCoO}_{2}$ of (A) DME and (B) ions at $507 \quad 1.2 \mathrm{~V}$ in $\mathrm{NO}_{3}^{-}$-free/containing electrolytes. (C) Schematics of interfacial adsorption and charge transfer process 508 on the positive electrode in a conventional dilute electrolyte. (D) Proposed mechanism for the solvent-exclusion 509 in the presence of $\mathrm{NO}_{3}{ }^{-} \mathrm{NO}_{3}{ }^{-}$adsorption prevents DME molecules from being adsorbed, thus preventing the 510 breakdown of DME. IHP, inner Helmholtz plane. OHP, outer Helmholtz plane. For clarity, the $\mathrm{Li}^{+}$ion 511 distributions near the electrode surface are not shown in schematic diagrams. 
A

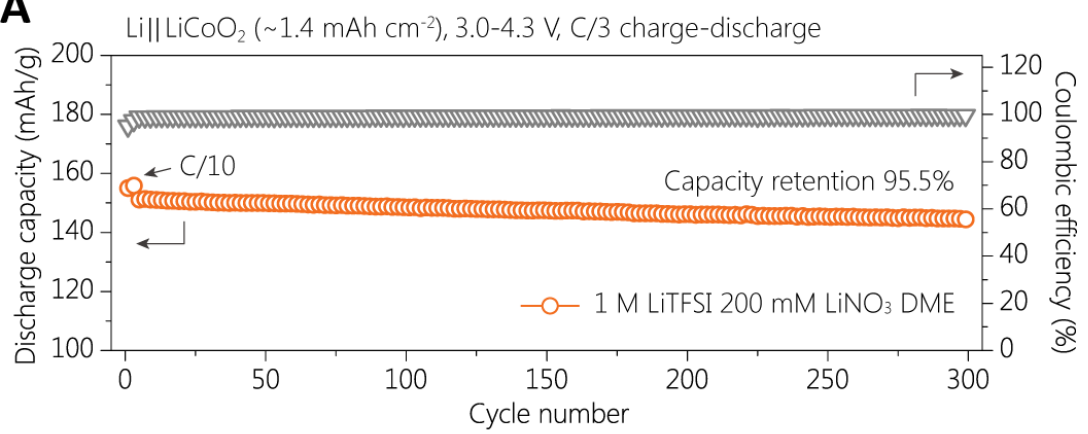

B

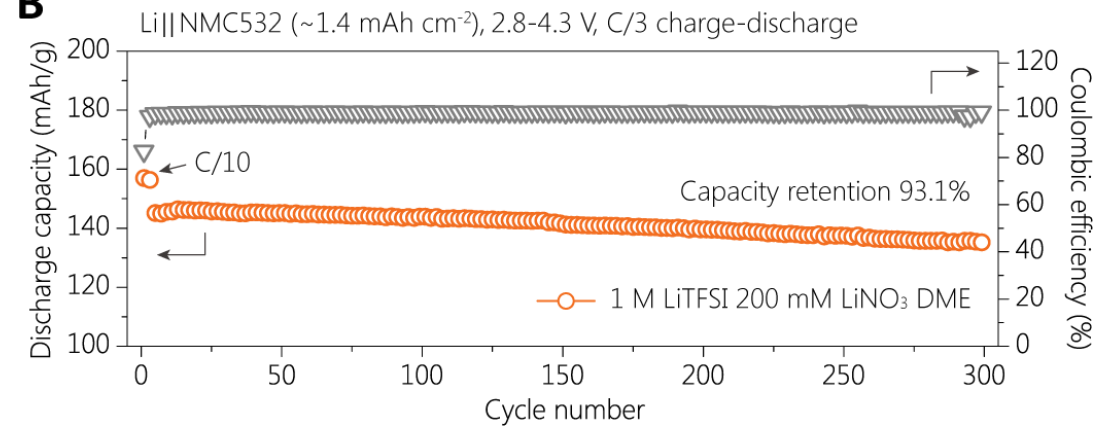

513 Figure 4. Electrochemical performances of $\mathrm{Li} \| \mathrm{LiCoO}_{2}$ and $\mathrm{Li} \| \mathrm{NMC532}$ cells in ether electrolytes under 514 higher areal capacities.

515 (A and B) Cycling stability of (A) $\mathrm{Li}|| \mathrm{LiCoO}_{2}$ and (B) Li||NMC532 batteries in $1 \mathrm{M}$ ether electrolyte with 200 $516 \mathrm{mM} \mathrm{LiNO}_{3}$ under $4.3 \mathrm{~V}$ charge cutoff voltage. The $\mathrm{Li} \|$ cathode cells were charged and discharged at a $\mathrm{C} / 3$ rate 517 after formation cycles at $\mathrm{C} / 10$, where $1 \mathrm{C}$ equals to $1.37 \mathrm{~mA} \mathrm{~cm}^{-2}$ for $\mathrm{LiCoO}_{2}$ cathode and $1.56 \mathrm{~mA} \mathrm{~cm}^{-2}$ for 518 NMC532 cathode, respectively. 


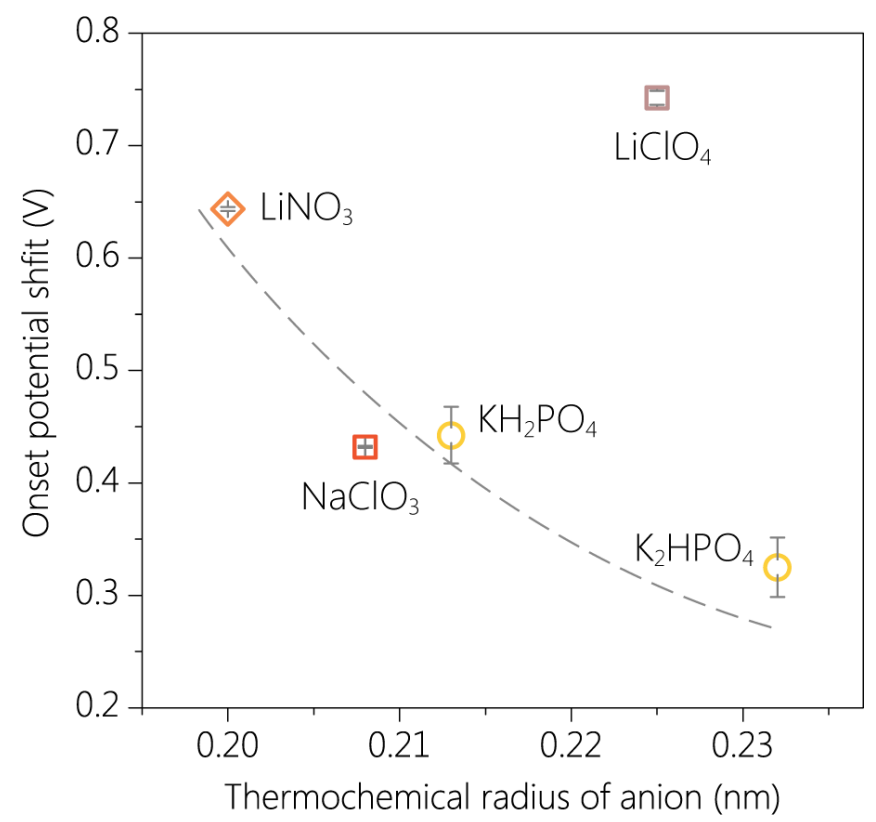

520 Figure 5. Impact of the additive anion type on the oxidation stability of ethers.

521 Relationship between onset potential shift and corresponding thermochemical radius of the anion. The error 522 bars are collected from the linear sweep voltammetry tests of electrolytes with different salt additives (Table 523 S1). The nearly linear shape for the onset potential shift with additive anion radius suggests that the geometric 524 size of anion matters to the ion interfacial packing. The dashed line is a guide for the eyes. 